\title{
Of Scents and Brain: Olfactory Stimulation for Neuropoeisis and Intervention for Neurodegenerative Disorders \\ Alvira Ali
}

Advance Educational Institute and Research Centre

Corresponding Author: Alvira@aeirc-edu.com

\section{Abstract}

Aromatherapy is an ancient scent treatment that has gained a lot of attention in the contemporary research for its various benefits. The role of olfactory stimulation leading to neuropoeisis has been a major consideration for treating neurodegenerative disorders like dementia, Alzheimer's and Parkinson's as well as psychiatric symptoms like mood disturbances, anxiety and sleep problems. The literature review has concentrated on the significance of the olfaction in the mammalian physiology and enlightened the hypothesis with noteworthy evidences to support the idea that with more research and clinical trials aromatherapy can attest to be a major breakthrough in treating Alzheimer's disease and reversing neurodegeneration.

\section{Keywords}

Aromatherapy, Neurpoeisis, Alzheimer's, Dementia, Neuro-degeneration

\section{Aromatherapy}

Aromatherapy is one of the simplest and natural approaches used for healing. Literally, it is a derivative of two different words: aroma meaning fragrance, smell or scent and therapy meaning remedy, cure or treatment (University of Maryland Medical Center, 2013). It is a blend of biological and manipulative techniques that uses the fragrances or scented oils usually with massage, acupuncture or any other suitable treatment (British Columbia, 2012). Thus, healing process involves the combination of two senses: touch and smell. The treatment is presumed to be helpful in supporting and balancing the mind, body and soul where each fragrance has a distinct effect on the nervous system and body. The practice involves the topical application, infusion in bath water, inhalation, and ingestion under strict supervision only. Yet, the manner of therapy is chosen according to the need of the consumer and requirement of the target. It is because each application has its own mode of action. For example, the inhalation of scents activates the limbic system while the topical application stimulates the thermal receptors of the dermis (Nordqvist, 2014 and Demetriou 2000).

\section{Research in Aromatherapy}

Clinical studies have showed that fragrances treatment provides relaxation from anxiety, stress, depression, cancer related symptoms, agitation in dementia, pain and quality of sleep (Najafi, et al, 2014, Williams, 2006, Holmes, et al, 2002, Ballard, et al, 2002, Fayazi, et al, 2011 and Diego, 1998).
Aromatic therapy relieves both the mental and physical stress and has a tendency of enhancing the parasympathetic nervous system and autonomic nervous system (Liu, et al, 2014, Glass, et al, 2013 and Chang K.M, et al, 2011).

\section{Senses; Smells and Behaviors}

Out of five senses, the aromatherapy engages two, touch and smell, for bringing upon the effects. These two senses are believed to have an emotional connection. For instance, the most sacred relationship of a Mother and her child bonds by these exceptionally strong senses (Demetriou, 2000). Studies show that babies tend to be finely sensitive towards the touch and scent of their biological mothers. These interactions bring physiological and psychological serenity to the babies and improve their growth and health (Agneta, 2014, Elizabeth et al, 2012, Delaunay-El, et al, 2010 and Doucet, et al, 2007). Baby's response to mother's touch positively elevates when is accompanied with the odor (Durand K, 2013).

The olfaction has an extraordinary significance in various physiological processes and psychological perceptions. For example, pheromones are the chemical substances secreted by the body of an animal that unlike all hormones, produce alterations in the physiology of other animals and not on one's own body (Mostafaa, et al, 2012 and Tirindeli R, et al, 2009). Pheromones provide individuals with their characteristic odor which allows baby to identify their mother and a person to distinguish their partner 
from others (Lundstorm, et al, 2013 and 2008 and Sobel N, et al, 2001).

Mammals have a distinct region in their olfactory system that senses the odors from pheromones and recognize them. The region is known as Vomeronasal Organ (Ogura, et al, 2010 and Tirindeli, et al, 2009) or Jacobson's Organ (Moran, et al, 1991), and is located in the nose (Brennan, et al, 2006). The neuronal cells of this organ synapses with the Amygdala and then Hypothalamus (Nordqvist, 2014). Olfaction of pheromones chiefly determines the physiology that fortifies the survival and is required for the determination of the sexual preferences, mating behavior, reproduction cycle, hormonal secretions, alertness, defensive nature, social behavior and territory mark (Woodley, et al, 2015; Dibattista, et al, 2012; Ogura, et al, 2010; Salazar, et al, 2009; Richard, et al, 2009; Snowdown, et al, 2006 and McClintock, 1998). Even though scents have similar effects on humans but it only plays a small role. It is because homosapiens have more developed and complex nervous system and evaluate situations and preferences with higher level of cognition (Mostafaa, et al, 2012).

Furthermore, pheromones have a very unusual function in some mammals like scientists have observed that when a pregnant mouse shares the vicinity with an unfamiliar male mouse, the pregnancy gets terminated naturally. This phenomenon is called the Bruce Effect and mainly involves the olfaction. The pregnant female senses the odor of a strange mouse, as the male secretes the pheromones. The scent influences the pregnancy in a way that it dampens the prolactin secretion in the female body. Prolactin is a precursor for progesterone and thus, the production of this hormone inhibits and as progesterone supports the gestation, the reduction causes the abortion. The nature is said to be adaptive because when new male animals take the dominancy, they do not father the unrelated baby, and rather they kill those newborns and mate with the females to give rise to their own bloodline. This adaptation saves the female from undergoing the stress of pregnancy and delivery, as the child would have no chances of living (Rajendren, et al, 1987, Yong, 2012 and Science Whiskers, 2012).

\section{Scents and Brain}

The sense of smell is found to be 10,000 times stronger than the other senses. A stimulus from sensing a fragrance travels more quickly towards the brain than others. It is estimated that our nose can sense 10,000 different scents distinctively (Nordqvist, 2014 and Damian, 1995). The stimulus of an odor is taken from the nasal reception to brain, where it stimulates the Amygdala and Hippocampus (Jorge, et al, 2014) in the Limbic System (Halcon, 2013). If the functions of these brain areas are summarized then it can be stated that amygdala holds the responsibility of generating an appropriate behavioral response while hippocampus determines the behavioral patterns and stores the memories (Guyton, 2010). Primarily, the reward and punishment centers are located in this region while hypothalamus is also responsible for the regulation of arterial pressures, heart rate, body temperature, thirst, water reabsorption from kidneys, uterine contractility, milk ejection, hunger, feeding reflexes and hormonal secretion from the anterior pituitary (Guyton, 2010). Thus, the fragrances can cause the alterations in body's physiological processes. The evidence of promising relationship between the hypothalamus, endocrine system and olfaction is the Kallmann Syndrome.

Kallmann syndrome is an X-linked genetic disorder which is characterized by the lack of olfactory perception and a delay in puberty. The mutated gene causes anomaly in the migration of olfactory receptor cells and gonadotropin releasing cells that disturbs the hypothalamus-pituitary axis that ultimately delays the puberty. Thus any defect in the olfactory bulb interrupts the communication between the hypothalamus and anterior pituitary gland (Lutz, et al, 1993 and Rugarli, et al, 1993).

It is also reported that scents have an ability to bring upon emotional changes in an individual depending on the consumer's perception and memory. This is called the Proust Effect, where a scent can evoke certain memories (Chen, 2013, Campen, 2013 and Hamilton, 2012).

\section{Olfactory System}

Evolutionary studies have confirmed that olfactory system is the oldest system that perceives the sensations in the mammalian body and has an ability to regenerate (Purves, 2001). The Olfactory Ensheathing Cells or OECs in the olfactory bulb provides the fascicles for the repair and regrowth of the mature olfactory neuronal cells. Scientists have been successful in utilizing regenerative properties of these cells by implanting them into the sites of spinal damage and successfully treating the lower body paralysis (BBC News, 2014).

The olfactory system has a prominence in all the sensory processes due to various reasons which may 
include the sensitivity, association with memory and behavior, harmony with endocrine functions and a reputation of being the oldest. Nonetheless, amongst all these the one peculiar aspect is that the olfactory sensations reach the cerebral cortex directly ( $\mathrm{Li}$, et al, 2007), without relaying information through the thalamus (Guyton, 2011). The electro-olfactogram further activates the nerves of the nervous system along the olfactory tract. The significance of olfactory nerve activation is its ability of potentiating the power of incoming stimulation. Hence, our nose holds a remarkable sensitivity even towards a small concentration of odor (Tortora, 2010).

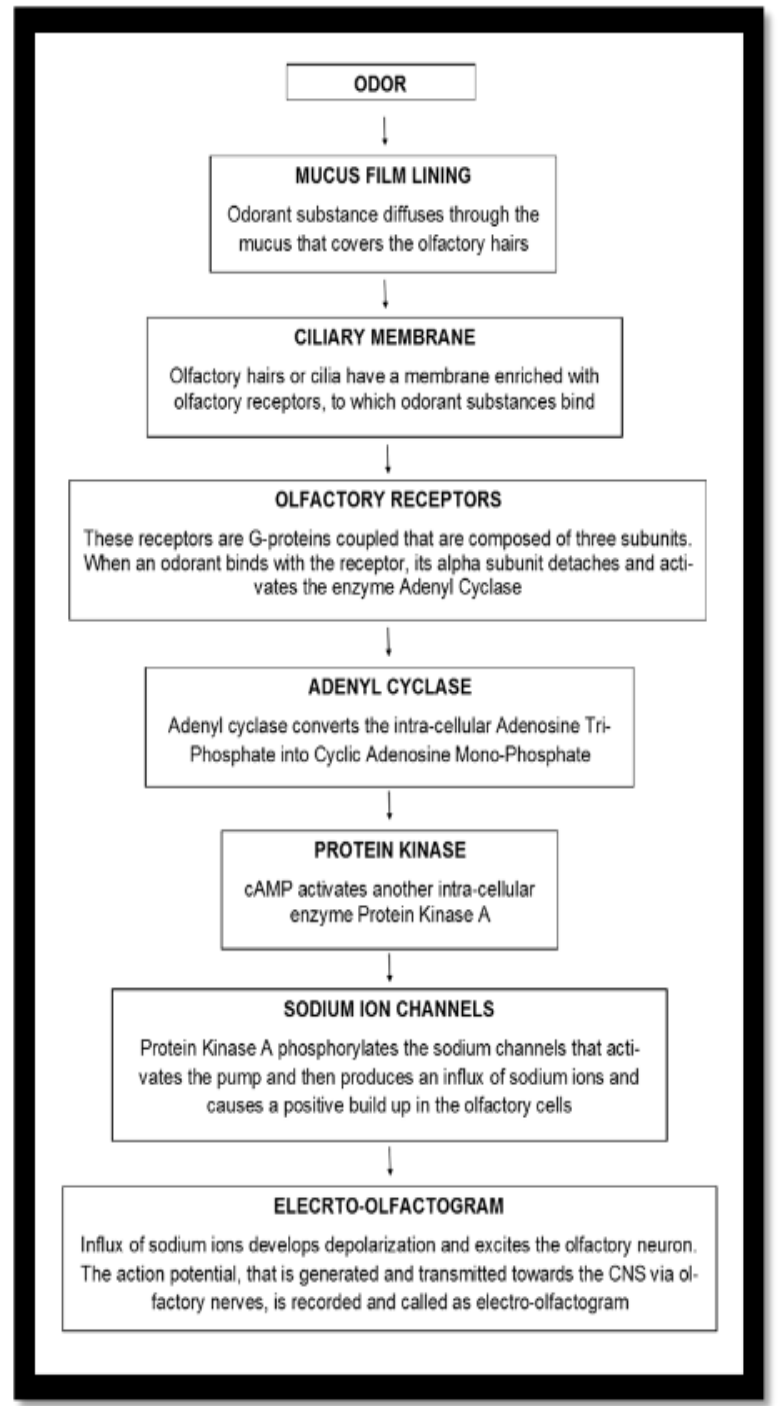

Figure: Stimulation of Olfactory Cells by the Odor and Activation of Electro-Olfactogram. (Adapted from Chen, et al, 2012, Guyton, 12th edition, Moran, 2007, Knecht, et al, 2004, Scott, et al, 2002 and Furukawa, et al, 1989).

\section{Conclusion}

Aromatherapy has gain a lot of attention in contemporary research for treating neurodegenerative conditions like dementia and psychiatric symptoms like anxiety, sleep problems and mood disturbances (Perry, et al, 2006). Although the neurophysiological, biochemical and pharmacological basis of the aromatic treatments are not well-recorded yet researchers are still working dedicatedly on the clinical trials to establish a ground for the efficacy of the techniques involving the scent therapies.

The aromatic treatment has been recently observed to have some influence on deteriorating cognitive functions and thus attained a status of interest in the domain of Alzheimer's disease. Anosmia, the loss of sense of smell, is often developed along with dementia in the AD because of the gradual neurodegeneration and development of neurofibrillary tangles and plaques. Neuroscientists have stated the fact that neurons in the olfactory bulb can undergo regeneration throughout the life. With regard to this observation, it is hypothesized that the olfactory excitation provided by the aromatherapy can help in stimulating the neuropoiesis in the olfactory bulb. As olfactory region tends to be directly in communication with the hippocampus and limbic system, it is believed that the neuronal regeneration reaches these regions and initiates neuropoeisis that ultimately improves the cognition and prevents further deterioration and memory loss (Jimbo, et al, 2009).

Working on these aspects with clinical trials and molecular studies can be a major breakthrough in treating Alzheimer's disease and other neurodegenerative conditions like dementia and Parkinson's. It is not though possible to utilize the benefits of aromatherapy without noting down the general effects and thus reliable evidence is required to include these therapies to the clinical practices. Therefore, thorough research is needed in future where these interventions can help with mental health issues and more studies involving physiological and biochemical analysis for learning the association between hormonal and neurotransmitters must also be performed.

\section{References}

- Agneta A.C, et al, 13 October 2014, "Parental Experiences of Providing Skin-to-Skin Care to their Newborn Infant - Part 1: A Qualitative Systemic Review", International Journal of Qualitative Studies on Health and Well-being, NCBI. 
- Ballard C.G, et al, July 2002, "Aromatherapy as a Safe and Effective Treatment for the Management of Agitation in Severe Dementia: The Results of a Double-Blind, Placebo-Controlled Trial with Melissa" PubMed.

- BBC News Report, Walsh F, 21 October 2014, "Paralyzed Man Walks Again After Cell Transplant” BBC News.

- Brennan P.A, et al, 8 November 2006, "Mammalian Social Odors: Attraction and Individual Recognition” PMCID.

- British Columbia, 16 October 2012, "Aromatherapy and Essential Oils" www.healthlinkbc.com.

- Campen C, 23 January 2013, "The Proust Effect The Senses as Doorways to Lost Memories" Oxford University Press.

- Chen J, 8 April 2013, “Aromatherapy: Allowing Scents to Heal Us" Huffington Post.

- Damian P and Damian K, 1995, "Aromatherapy: Scent and Psyche: Using Essential Oils for Physical and Emotional Well-Being" page 1-3, 67, 11-12, 15-19, 25-28 and 108-109.

- Delaunay-El Allam M, et al, November 2010 "Long Lasting Memory for an Odor Acquired at Mother's Breast", Wiley Online Library.

- Demetriou M.C and Demetriou A.J, 2000, "Integrating Complementary and Conventional Medicine" page 1-21, 45-47, 49-50.

- Dibattista M, et al, July 2012, "CalciumActivated Chloride Channels in the Apical Region of Mouse Vomeronasal Sensory Neurons" PMC.

- Diego M.A, et al, December 1998, "Aromatherapy Positively Affects Mood, EEG Patterns of Alertness and Math Computations" PubMed.

- Doucet S, et al, March 2007, “The 'Smellscape' of Mother's Breast: Effects of Odor Masking and Selective Unmasking on Neonatal Arousal, Oral, and Visual Responses", Developmental Psychobiology, PubMed.

- Durand K, et al, 28 August 2013, "Eye Catching Odors: Olfaction Elicits Sustained Gazing to Faces and Eyes in 4 Months Old Infants", PLOS, NCBI.

- Elizabeth R.M, et al, 16 May 2012, "Early Skinto-Skin Contact for Mothers and their Healthy Newborn Infants", PMC, NCBI.

- Fayazi S, et al, 2011, "The Effect of Inhalation Aromatherapy on Anxiety Level of the Patients in Preoperative Period" PMCID.

- Furukawa M, et al, 1989, "Electro-Olfactogram (EOG) in Olfactometry” PubMed.
- Guyton and Hall, "Textbook of Medical Physiology", 12th Edition, Chapter 58, page 714 720.

- Halcon L, 16 July 2013, "How Do Essential Oils Work?" University of Minnesota.

- Hamilton P, September 2012, "The Proust Effect: Oral History and the Senses" The Oxford Handbook of Oral History.

- Holmes C, et al, April 2002, "Lavender Oil as a Treatment for Agitated Behavior in Severe Dementia: A Placebo Controlled Study" PubMed.

- Jimbo D, Kimura Y, Taniguchi M, Inoue M and Urakami K, 2009, "Effect of aromatherapy on patients with Alzheimer's disease" DOI: 10.1111/j.1479-8301.2009.00299.x.

- Jorge P.E, et al, 22 May 2014, “Odors Stimulate Neuronal Activity in the Dorsolateral Area of the Hippocampal Formation during Path Integration" PMCID.

- Knecht M, et al, 30 October 2004, "Special Section on Olfactory Perception, Communication, and the Nose-to-Brain Pathway" Physiology \& Behavior, Volume 83, Issue 1, Pages 13-19.

- Li W, et al, December 2007, "Subliminal Smells can Guide Social Preferences" PubMed.

- Lundstrom J.N, et al, 11 March 2013, "Functional Neuronal Processing of Human Body Odors" PMCID.

- Lundstrom J.N, et al, June 2008, "Functional Neuronal Processing of Body Odors Differs from that of Similar Common Odors" PubMed.

- Lutz B, et al, 28 June 1993, "X-Linked Kallmann Syndrome. A Neuronal Targeting Defect in the Olfactory System?” PubMed.

- McClintock M.K, 1998, "On the Nature of Mammalian and Human Pheromones" Annals of the New York Academy of Sciences, Volume 855, Pages 390-392.

- Moran D.T, et al, October 1991, "The Vomeronasal (Jacobson's) Organ in Man: Ultrastructure and Frequency of Occurrence" The Journal of Steroid Biochemistry and Molecular Biology, Volume 39, Issue 4, Part 2.

- Mostafaa T, et al, January 2012, "Pheromones in Sex and Reproduction: Do they have a Role in Humans?" Journal of Advanced Research, Volume 3, Issue 1, Pages 1-9.

- Najafi Z, et al, 5 August 2014, “The Effects of Inhalation Aromatherapy on Anxiety in Patients with Myocardial Infarction: A Randomized Clinical Trial” PMCID. 
- Nordqvist C, 15 September 2014, "What is Aromatherapy? The Theory Behind Aromatherapy" Medical News Today.

- Ogura T, et al, 30 July 2010, “Chemoreception Regulates Chemical Access to Mouse Vomeronasal Organ: Role of Solitary Chemosensory Cells" PMC.

- Perry, 2006, "Aromatherapy in the Management of Psychiatric Disorders: Clinical and Neuropharmacological Perspectives" Perry, N. \& Perry, E. CNS Drugs (2006) 20: 257. doi:10.2165/00023210-200620040-00001.

- Purves D, "Neuroscience", 2nd Edition, Sunderland (MA): Sinauer Associates; 2001, Book-Shelf, NCBI. ISBN-10: 0-87893-742-0.

- Rajendren G, et al, April 1987, "The MaleInduced Pregnancy Block (The Bruce Effect) in Mice: Re-Evaluation of the Ability of Exogenous Progesterone in Preventing Implantation Failure" PubMed.

- Richard L, et al, March 2009, "Sex Difference and Reproductive Hormone Influences on Human Odor Perception" PMC.

- Rugarli E.I, et al, 1993, "Expression Pattern of the Kallmann Syndrome Gene in the Olfactory System Suggests a Role in Neuronal Targeting" Nature Genetics.

- Salazar I, et al, 30 October 2009, "The Risk of Extrapolation in Neuroanatomy: The Case of the Mammalian Vomeronasal System" PMC.
- Scott J.W, et al, 1 August 2002, "The ElectroOlfactogram: A Review of its History and Uses" PMC.

- Science Whiskers, 20 August 2012, "The Bruce Effect".

- Snowdown C.T, et al, 6 November 2006, "Social Odors, Sexual Arousal and Pair-Bonding in Primates" PMCID.

- Sobel N, et al, 30 August 2001, "The Scented Brain: Pheromonal Responses in Humans" Neuron, Volume 31, Issue 4, Pages 512-514.

- Tirindeli R, et al, 1 July 2009, "From Pheromones to Behavior" American Physiological Society Journal, Volume 89.

- Tortora G.J and Derrickson B.H, "Principles of Anatomy and Physiology" 12th edition.

- University of Maryland, Medical Center, 7 May 2013, "Aromatherapy".

- Williams T.I, 16 March 2006, "Evaluating Effects of Aromatherapy Massage on Sleep in Children with Autism: A Pilot Study" Evidence-Based Complementary and Alternative Medicine, Volume 3, Issue no. 3, page 373-377.

- Woodley S.K, et al, 14 November 2015, "Effects of Vomeronasal Organ Removal on Olfactory Sex Discrimination and Odor Preferences of Female Ferrets", PMC.

- Yong E, 23 February 2012, “The Bruce Effect Why Some Pregnant Monkeys Abort when New Males Arrive" www.blog.discoverscience.com 